\title{
Microstructure of an Addition Polymer Composed of 1,4-Benzenedithiol and 1,4-Diethynylbenzene
}

\author{
Eiichi KOBAYASHI, Toyoshi OHASHI, ${ }^{*}$ and Junji FuruKaWA \\ Department of Industrial Chemistry, Faculty of Science and Technology, \\ Science University of Tokyo, Noda 278, Japan \\ * On leave from Mitsubishi Petrochemical Co., 2-5-2 Marunouchi, \\ Chiyoda-ku, Tokyo 100, Japan
}

(Received July 22, 1988)

\begin{abstract}
The microstructures of addition polymers composed of 1,4-benzenedithiol (BDT) and 1,4-diethynylbenzene (DEB) were studied by IR method. As model compounds for the assignment of the IR spectra, the compound [A] cis-cis and the compound [B] trans-trans were
\end{abstract} used.

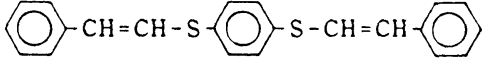

[A]

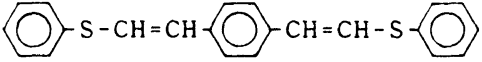

[B]

The characteristic absorption peak of the cis-linkage of the model compounds was assigned to be $1350 \mathrm{~cm}^{-1}$ ( $\varepsilon$ in $1 \mathrm{~mol}^{-1} \mathrm{~cm}^{-1} ; 122.1$ in $\left.\mathrm{CCl}_{4}\right)$ and that of the trans-linkage was $940 \mathrm{~cm}^{-1}(\varepsilon$ in $1 \mathrm{~mol}^{-1} \mathrm{~cm}^{-1} ; 311.6$ in $\left.\mathrm{CCl}_{4}\right)$ in the IR spectra. The microstructures of the polymers were quantitatively estimated by the following equations.

$$
C_{\text {cis }}=7.80 \times 10^{-3} D_{1350}-2.10 \times 10^{-4} D_{940}
$$

and

$$
C_{\text {trans }}=3.20 \times 10^{-3} D_{940}-3.21 \times 10^{-4} D_{1350}
$$

where $C_{\text {cis }}$ and $C_{\text {trans }}$ mean the concentrations of the cis- and the trans-linkage in the polymers, and $D_{1350}$ and $D_{940}$ are the absorbances of the cis-linkage at $1350 \mathrm{~cm}^{-1}$ and the trans-linkage at $940 \mathrm{~cm}^{-1}$, respectively. The microstructures of polymers obtained in the toluene solution under UV-irradiation were found to be mainly the cis-structure, regardless of the polymerization temperature $\left(0^{\circ} \mathrm{C}\right.$, cis $95 \% ; 60^{\circ} \mathrm{C}$, cis $\left.88 \%\right)$. However, the cis-contents of the polymers obtained in solid state under UV-irradiation decreased with increasing polymerization temperature $\left(0^{\circ} \mathrm{C}\right.$, cis $94 \% ; 60^{\circ} \mathrm{C}$, cis $81 \% ; 80^{\circ} \mathrm{C}$, cis $73 \%$ ). The polymerization mechanism in the solid state may differ from that in solution. The arrangement and mobility of the reacting molecules in the crystalline solid probably affect the opening mode of the acetylenic triple bond. These phenomena are briefly discussed.

KEY WORDS Microstructure of Addition Polymer / 1,4-Benzenedithiol / 1,4-Diethynylbenzene/ Solid State Polymerization/ Solution Polymerization / IR Spectrum / cis-Linkage / trans-Linkage / Model Compounds / cis-trans Isomerization /

Free-radical addition reaction of thiols to monosubstituted acetylene has been known for more than 50 years ${ }^{1}$ and occurs in an antiMarkownikoff manner. ${ }^{2}$ However, the addition polymerization of a dithiol to a com- pound having one or two ethynyl groups has scarcely been known except the case for the addition polymerization of hydrogen sulfide to acetylene ${ }^{3}$ and the addition polymerization of 1,2-ethanedithiol or 1,6-hexanedithiol to 1,4- 
bis(acetylenic keto)benzene. ${ }^{4}$ In the former case, hydrogen sulfide and acetylene were irradiated with a low pressure mercury lamp and the HS - radical produced in the direct photolysis was added to acetylene to form the radical, $\mathrm{HSCHCH} \cdot$. Ethenethiol was produced by the abstraction of hydrogen from hydrogen sulfide. Consequently, a rapid polymerization of ethenethiol occurred and gave the polymer having the general formula $\left(\mathrm{C}_{2} \mathrm{H}_{4} \mathrm{~S}\right)_{n}$. In the latter case, ${ }^{4}$ the addition polymerization was also found to proceed rapidly. Although the cis-configuration of the enonesulfide is assumed to form as below, the exact configuration of the repeat unit has not yet been determined.

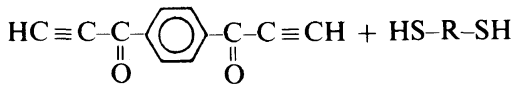

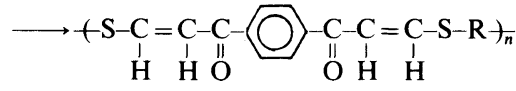

$$
\begin{aligned}
& \mathrm{R}: \quad\left(\mathrm{CH}_{2}\right)_{2},\left(-\mathrm{CH}_{2}\right)_{6}
\end{aligned}
$$

Previously, the authors reported the addition polymerization of 1,4-benzenedithiol to 1,4-diethynylbenzene in the solution ${ }^{5}$ and also in the solid state. ${ }^{6}$ In the solid state polymerization the polymer obtained exhibits high crystallinity. The crystallinity was affected by photo-irradiation. ${ }^{7}$ For instance, in the region from 500 to $600 \mathrm{~nm}$ there are three characteristic wavelengths of 545.6, 567.8, and $590.1 \mathrm{~nm}$. The irradiation at these lights in- creases the crystallinity of the polymers. On the other hand, the photo-light of 501.1, 539.6, and $588.1 \mathrm{~nm}$ decreases steeply the peak intensity of the diffractions in the X-ray diagram According to a preliminary investigation the present polymer possesses a layer structure with an orthorombic lattice. ${ }^{8}$ The peak intensity in the X-ray diagram seems to be associated with the amount of the layer structure. The $c i s-$ trans isomerization in the polymer molecules by photo-irradiation may affect the stability of the layer structure.

This report deals with the microstructure of the addition polymers composed of 1,4-benzenedithiol and 1,4-diethynylbenzene, and briefly discusses the relation between the microstructure and layer structure of polymers.

\section{EXPERIMENTAL}

\section{1,4-Benzenedithiol (BDT) and 1,4-Diethynyl- benzene (DEB)}

BDT and DEB were prepared by the previous method. ${ }^{6}$ BDT was recrystallized from $n$-hexane solution, and then sublimed at $70^{\circ} \mathrm{C}$ under reduced pressure prior to use. DEB was purified by recrystallization from $n$ hexane solution, and then sublimed at $60^{\circ} \mathrm{C}$ under reduced pressure prior to use.

\section{Model Compounds}

The model compounds for assignments of the IR spectrum of polymers were synthesized by the previous method. ${ }^{9}$

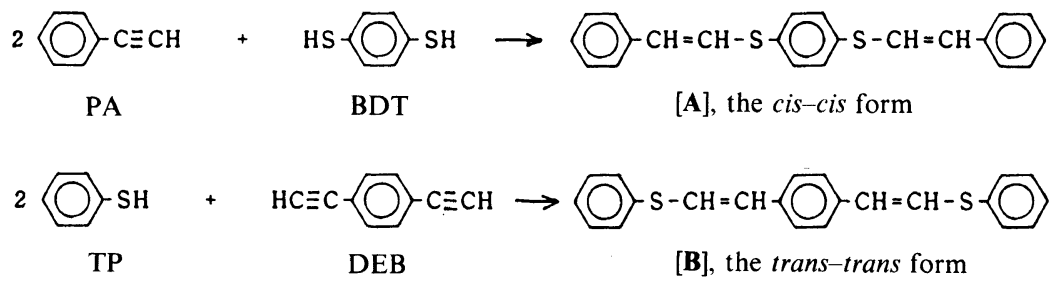

\section{Solution and Solid State Polymerization}

The solution ${ }^{5}$ and solid state ${ }^{6}$ polymerizations were carried out as previously re- ported. The photo-irradiation polymerizations were carried out by high pressure mercury lamp of $450 \mathrm{~W}$ (USHIO). 


\section{Measurement}

Model compounds ([A],[B]) were analyzed by ${ }^{1} \mathrm{H}-\mathrm{NMR}$ (JEOL JNM-FX 270) and IR(Hitachi 260-50 and Hitachi EPI-S2). UV spectra and DSC of the model compounds were measured by a Shimadzu UV-260 and a Rigaku TAS-100, respectively.

The characteristic absorption peaks and their extinction coefficients $(\varepsilon)$ of the cis- and the trans-compounds were determined by the
IR method in a solution such as that of $\mathrm{CCl}_{4}$ or $\mathrm{CS}_{2}$.

\section{RESULTS AND DISCUSSION}

Previously, the authors reported the addition polymerization of BDT to DEB under $\mathrm{UV}$-irradiation in toluene solution ${ }^{5}$ and in the solid state. ${ }^{6}$ The reaction scheme is as follows.

$$
\mathrm{HS}-\mathrm{O}-\mathrm{SH}+\mathrm{HC} \equiv \mathrm{C}-\mathrm{C}-\mathrm{C} \equiv \mathrm{CH} \underset{\text { solution or solid state }}{\longrightarrow}+\mathrm{S}-\mathrm{O}-\mathrm{S}-\mathrm{CH}=\mathrm{CH}-\mathrm{O}-\mathrm{CH}=\mathrm{CH})_{n}
$$

The polymer structure coincides with the IR spectrum of polymers taken with the $\mathrm{KBr}$ disk method. However, the configuration of the vinylene group had not yet been determined. The model compounds are useful for assignment of the microstructures of polymers.

\section{Model Compounds [A] and [B]}

${ }^{1} \mathrm{H}-\mathrm{NMR}$ spectra of $[\mathrm{A}]$ and $[\mathrm{B}]$ are shown in Figure 1. Fourteen protons on the aromatic rings of the compound [A] appear in the range of $\delta 7.1$ to 7.5 , and four protons of the vinylene group are centered at $\delta 6.53$ and 6.37 as the AB quartet type. The coupling constant of the vinylene protons $J_{\mathrm{C}}=\mathrm{C} \underline{\mathrm{H}}$ is $10.5 \mathrm{~Hz}$ indicating the cis-linkage. On the other hand, the fourteen protons on the aromatic rings of the compound [B] are located in the range of $\delta 7.2$ to 7.5. The chemical shift values for the four protons of the vinylene group are $\delta 6.88$ and 6.67 as also for the $\mathrm{AB}$ quartet type. The coupling constant $J_{\mathrm{CH}=\mathrm{CH}}$ is $15.5 \mathrm{~Hz}$ suggesting the trans-linkage of the compound [B]. These assignments are consistent with the ${ }^{1} \mathrm{H}$ NMR data taken with the cis-adduct $(10.5 \mathrm{~Hz}$ and trans-adduct $(15.5 \mathrm{~Hz})$ of thiophenol and phenylacetylene. $^{10}$

Figure 2 shows the IR spectra of $[\mathbf{A}]$ and $[\mathbf{B}]$. The $-\mathrm{CH}=$ stretching vibrations of aromatic rings and methyne groups appear at 3,075, $3,025 \mathrm{~cm}^{-1}$. The $\mathrm{C}=\mathrm{C}$ skeletal stretching mode, the $-\mathrm{CH}=$ in-plane and the $-\mathrm{CH}=$ out- of-plane vibrations of aromatic rings can be found at $1,600-1,450 \mathrm{~cm}^{-1}, 1,250-1,000$ $\mathrm{cm}^{-1}$, and $850-650 \mathrm{~cm}^{-1}$, respectively. Generally, the vibrations of the symmetrically disubstituted trans-ethylenes appear at wave numbers between 970 and $930 \mathrm{~cm}^{-1,11 \mathrm{a}}$ but the $-\mathrm{CH}=$ out-of-plane deformation vibration of the cis-adducts cannot easily be assigned because of overlapping with the $-\mathrm{CH}=$ deformation vibrations of the aromatics and vinylene of the cis-adduct. ${ }^{11 \mathrm{~b}}$ However, as shown in Figure 2(a) and (b), the characteristic absorption peak of the $-\mathrm{CH}=$ out-of-plane deformation vibration of the $[\mathbf{A}]$ cis-cis adduct can be assigned at $1,350 \mathrm{~cm}^{-1}$ and that of the [B] trans-trans adduct, at $940 \mathrm{~cm}^{-1}$. The characteristic absorption peak at $1,350 \mathrm{~cm}^{-1}$ is recognized in the cis-adduct prepared from TP and PA, and similarly the absorption at $940 \mathrm{~cm}^{-1}$ is recognized with the trans-adduct of TP and PA. Therefore, the bands at 1,350 and $940 \mathrm{~cm}^{-1}$ can be ascribed to the characteristic modes for the cis- and trans-linkage, respectively.

Table I summarizes the spectroscopic data with the UV spectrum and the IR spectrum of the model compounds.

The extinction coefficient $(\varepsilon)$ of the $c i s-c i s$ adduct at $1,350 \mathrm{~cm}^{-1}$ is $122.1\left(1 \mathrm{~mol}^{-1} \mathrm{~cm}^{-1}\right)$ in the $\mathrm{CCl}_{4}$ solution and 126.9 in the $\mathrm{CS}_{2}$ solution at $23^{\circ} \mathrm{C}$. Similarly, the $\varepsilon$ of the transtrans adduct at $940 \mathrm{~cm}^{-1}$ is $311.6\left(1 \mathrm{~mol}^{-1}\right.$ 


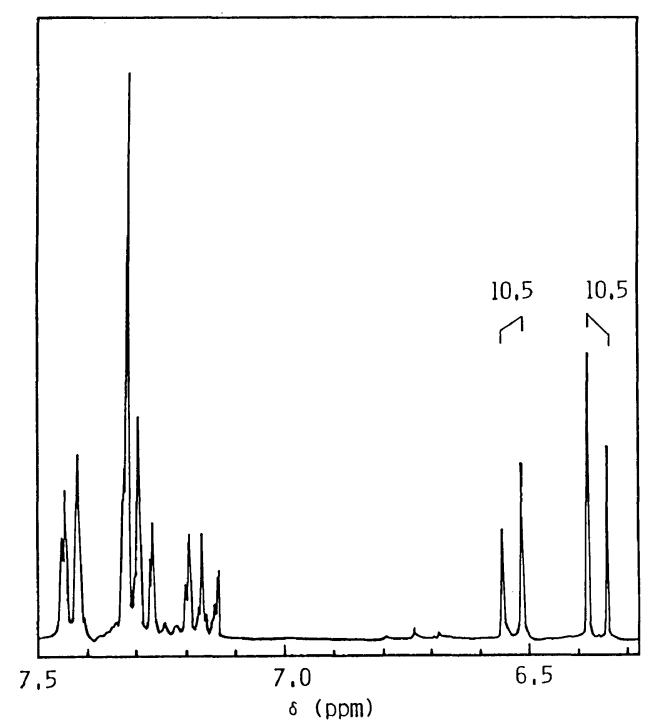

a)

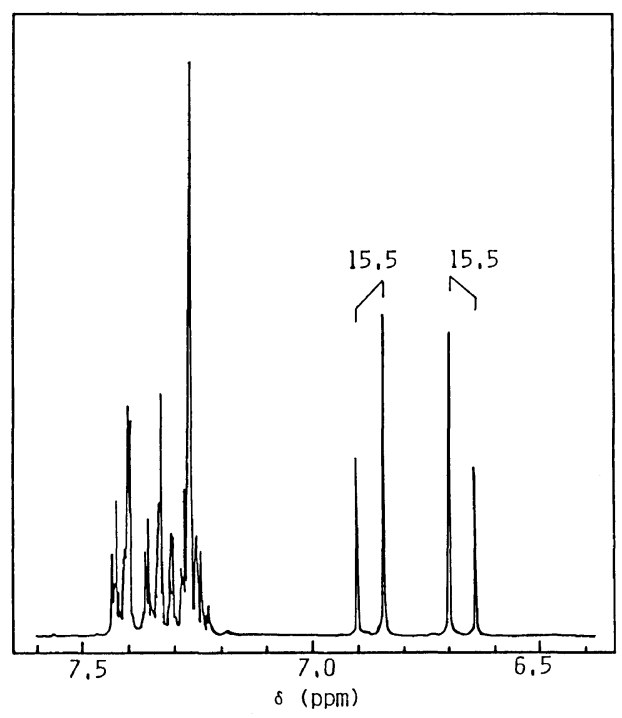

b)

Figure 1. ${ }^{1} \mathrm{H}$ NMR spectra of model compounds in $\mathrm{CDCl}_{3}$ at $35^{\circ} \mathrm{C}$ (TMS standard): (a) [A], cis-cis form<smiles>C1=CC(=CC=Cc2ccccc2)C=CC=1SC=Cc1ccccc1</smiles>

(b) $[\mathbf{B}]$,

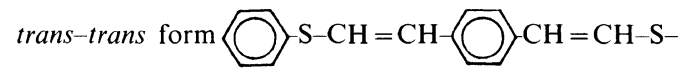<smiles>c1ccccc1</smiles>
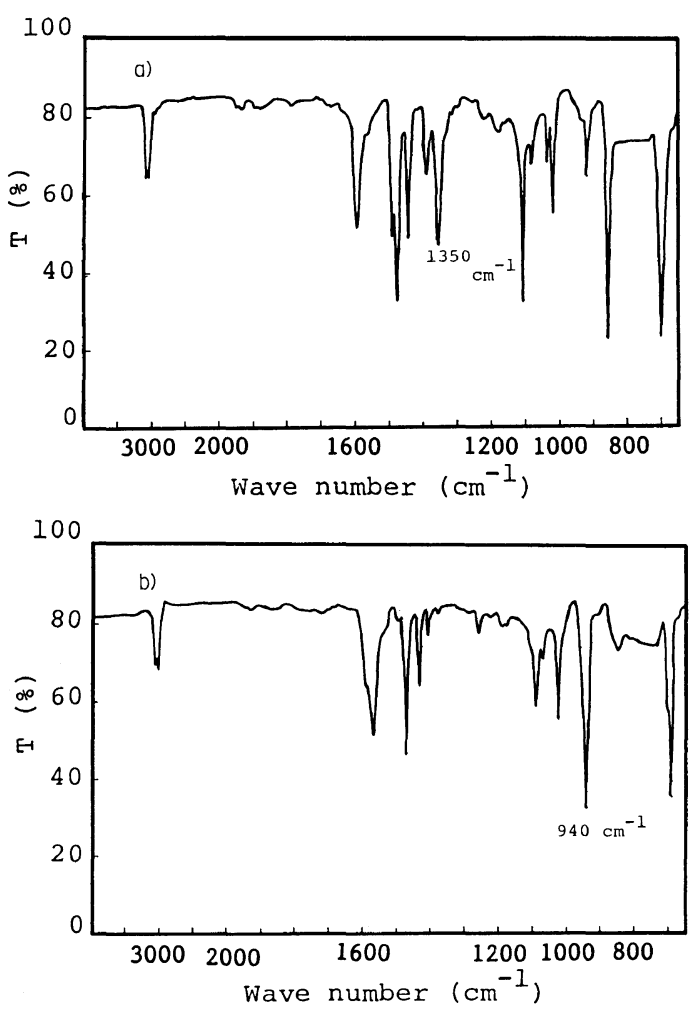

Figure 2. IR spectra of model compounds in $\mathrm{CCl}_{4}$ at $23^{\circ} \mathrm{C}$ (Hitachi EPI-S2): (a) [A], cis-cis form $\mathrm{CH}=$ $\mathrm{CH}-\mathrm{S} \bigcirc \mathrm{S}-\mathrm{CH}=\mathrm{CH} \bigcirc ;$ (b) [B], trans-trans form (O- $-\mathrm{CH}=\mathrm{CH}-\mathrm{CH}=\mathrm{CH}-\mathrm{S} \bigcirc$.

$\mathrm{cm}^{-1}$ ) in the $\mathrm{CCl}_{4}$ solution and 355.7 in the $\mathrm{CS}_{2}$ solution at $23^{\circ} \mathrm{C}$. However, the $\varepsilon$, values of the cis- and trans-linkage of polymers cannot be directly determined because of the insolubility of polymers in conventional organic solvents. Accordingly, the $\varepsilon$ values used for the microstructure analysis of polymers are tentatively selected to be the average values of the of $[\mathbf{A}]$ or $[\mathbf{B}]$ in $\mathrm{CCl}_{4}$ and in $\mathrm{CS}_{2}$. Under this assumption the relation between the concentration of the cis-structure $\left(C_{c i s}\right)$ and the trans-one $\left(C_{\text {trans }}\right)$ in the mixture of the cis-cis adduct and the trans-trans adduct is determined by the following equations, where $D_{1350}$ and $D_{940}$ mean the absorbances at 1,350 and $940 \mathrm{~cm}^{-1}$, respectively. 
Table I. Spectroscopic data of model compounds

\begin{tabular}{|c|c|c|c|c|}
\hline & $\underset{c i s}{O}$ & $\underbrace{9}_{\text {trans }}$ & $\begin{array}{c}{[\mathbf{A}]^{9}} \\
\text { cis-cis }\end{array}$ & $\begin{array}{c}{[\mathbf{B}]^{9}} \\
\text { trans-trans }\end{array}$ \\
\hline $\mathrm{mp}^{\mathrm{a}}\left({ }^{\circ} \mathrm{C}\right)$ & $\begin{array}{r}48.8-49.2 \\
\left(44-46^{12}\right)\end{array}$ & $\begin{array}{c}38.6-39.5 \\
\left(35-36^{10}\right)\end{array}$ & $130.5-131.0$ & $122.7-123.0$ \\
\hline \multicolumn{5}{|l|}{$\mathrm{UV}$-spectrum at $22^{\circ} \mathrm{C}^{\mathrm{b}}$} \\
\hline$\lambda_{\max }(\mathrm{nm})$ & $\begin{array}{c}295.7 \\
\left(296^{10}\right)\end{array}$ & $\begin{array}{c}306.9 \\
\left(304^{10}\right)\end{array}$ & 312.4 & 343.5 \\
\hline$\varepsilon\left(1 \mathrm{~mol}^{-1} \mathrm{~cm}^{-1}\right)$ & $\begin{array}{c}21,000 \\
\left(19,000^{10}\right)\end{array}$ & $\begin{array}{c}20,000 \\
\left(20,000^{10}\right)\end{array}$ & 48,000 & 44,000 \\
\hline $\begin{array}{l}\text { IR-spectrum at } 23^{\circ} \mathrm{C} \\
\text { Wave number }\left(\mathrm{cm}^{-1}\right) \\
\varepsilon\left(1 \mathrm{~mol}^{-1} \mathrm{~cm}^{-1}\right)\end{array}$ & 1,350 & 940 & 1,350 & 940 \\
\hline $\mathrm{CCl}_{4}$ & 55.7 & 147.2 & 122.1 & 311.6 \\
\hline $\mathrm{CS}_{2}$ & 55.9 & 157.8 & 126.9 & 355.7 \\
\hline
\end{tabular}

a Determined by DSC.

b Measured in hexane solution.

$$
\begin{gathered}
C_{\text {cis }}=7.80 \times 10^{-3} D_{1350}-2.10 \times 10^{-4} D_{940} \\
C_{\text {trans }}=3.20 \times 10^{-3} D_{940}-3.21 \times 10^{-4} D_{1350} \\
\operatorname{cis}(\%)=C_{\text {cis }} /\left(C_{\text {cis }}+C_{\text {trans }}\right) \times 100 \\
\operatorname{trans}(\%)=C_{\text {trans }} /\left(C_{\text {cis }}+C_{\text {trans }}\right) \times 100
\end{gathered}
$$

These equations can be used for estimation of the microstructures of polymers. However, it is noticed that the microstructures of polymers evaluated by this method may have error, since the extinction coefficients of polymers are not only assumed to be the same as those of model compounds $[\mathbf{A}]$ and $[\mathbf{B}]$, but also the IR spectra of polymers were measured by the $\mathrm{KBr}$ method.

\section{Microstructure of Polymers}

Figure 3 shows the IR spectrum of polymer obtained by the solid state polymerization. The characteristic absorption peaks of the cisand trans-linkage appear at 1,350 and at $940 \mathrm{~cm}^{-1}$. Using the above equations the $\mathrm{mi}-$ crostructure of the polymer is estimated to be that the cis content is $72 \%$ and the trans one is $28 \%$.

Table II shows the effect of the polymerization temperature and that of the initiation mode on the microstructure of polymers ob-

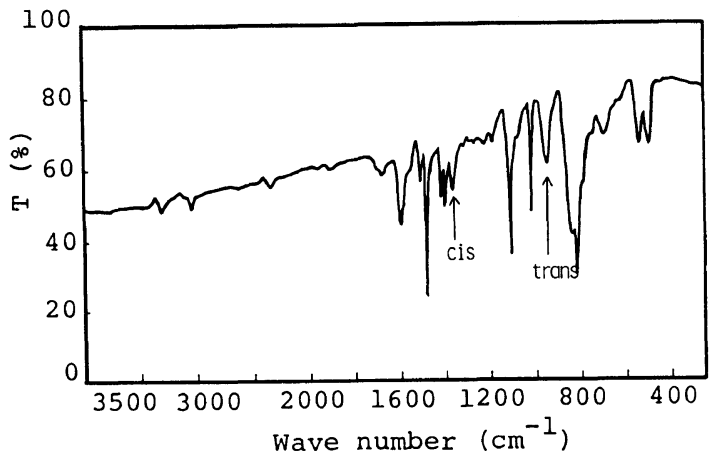

Figure 3. IR spectrum of a polymer obtained in solid state polymerization at $60^{\circ} \mathrm{C}$ under UV-irradiation by a high pressure mercury lamp of $450 \mathrm{~W}$ (Hitachi 260-50, $\mathrm{KBr}$ method).

tained by solution polymerization.

In the case of UV-irradiation polymerization, the microstructures of polymers were found to be mainly cis-structures regardless of polymerization temperature, but the cis- content in the polymers slightly decreases with increasing the polymerization temperature. The initiation modes such as UV, AIBN, and BPO have little effect on the content of the cislinkage. The cis-structure was favored in the solution polymerization. On the other hand, the cis-content in polymers decreases with increasing polymerization temperature in solid 
Table II. Effects of polymerization temperature and initiation mode on microstructures of polymers obtained by solution polymerization in toluene

\begin{tabular}{|c|c|c|c|c|c|}
\hline \multirow{2}{*}{ No. } & \multirow{2}{*}{$\frac{\text { Polymn. temp }}{{ }^{\circ} \mathrm{C}}$} & \multirow{2}{*}{$\begin{array}{c}\text { Polymn. time } \\
\min \end{array}$} & \multirow{2}{*}{$\begin{array}{l}\text { Initiation } \\
\text { mode }^{\mathrm{a}}\end{array}$} & \multirow{2}{*}{$\frac{\text { Yield }}{\%}$} & \multirow{2}{*}{ cis/trans ${ }^{\mathrm{b}}$} \\
\hline & & & & & \\
\hline 1 & 0 & 10 & UV & 31.7 & $95 / 5$ \\
\hline 2 & 0 & 40 & UV & 59.7 & $99 / 1$ \\
\hline 3 & 30 & 10 & UV & 42.5 & $94 / 6$ \\
\hline 4 & 30 & 30 & UV & 66.1 & $91 / 9$ \\
\hline 5 & 30 & 30 & AIBN & 20.5 & $90 / 10$ \\
\hline 6 & 30 & 30 & BPO & 22.6 & $94 / 6$ \\
\hline 7 & 60 & 10 & UV & 61.7 & $88 / 12$ \\
\hline 8 & 60 & 10 & AIBN & 58.7 & $92 / 8$ \\
\hline \multirow[t]{2}{*}{9} & 60 & 10 & BPO & 53.9 & $94 / 6$ \\
\hline & & & & (Average value) & $93 / 7$ \\
\hline
\end{tabular}

$[\mathrm{BDT}]=[\mathrm{DEB}]=0.4 \mathrm{moll}^{-1}$ in toluene.

a UV, high pressure mercury lamp of $450 \mathrm{~W}$; [AIBN] $=[\mathrm{BPO}], 1 / 100 \mathrm{~mol} \%$ for monomer concentration.

b Hitachi $260-50, \mathrm{KBr}$ method.

Table III. Effect of polymerization temperature on microstructures of polymers obtained by solid state polymerization under UV-irradiation ${ }^{\mathrm{a}}$

\begin{tabular}{|c|c|c|c|c|}
\hline \multirow{2}{*}{ No. } & Polymn. temp & Polymn. time & Yield & \multirow{2}{*}{ cis/trans } \\
\hline & ${ }^{\circ} \mathrm{C}$ & $\min$ & $\%$ & \\
\hline 1 & 0 & 15 & 28 & $94 / 6$ \\
\hline 2 & 0 & 40 & 54 & $89 / 11$ \\
\hline 3 & 30 & 15 & 72 & $87 / 13$ \\
\hline 4 & 30 & 40 & 85 & $87 / 13$ \\
\hline 5 & 60 & 5 & 78 & $82 / 18$ \\
\hline 6 & 60 & 10 & 87 & $81 / 19$ \\
\hline 7 & 80 & 3 & 89 & $74 / 26$ \\
\hline 8 & 80 & 10 & 98 & $73 / 27$ \\
\hline
\end{tabular}

Sublimation conditions of monomers on a glass plate: $60^{\circ} \mathrm{C}, 5 \mathrm{~min}, 0.5 \mathrm{mmHg}$; cooling water, $9.8-10.9^{\circ} \mathrm{C}$.

${ }^{a}$ High pressure mercury lamp of $450 \mathrm{~W}$.

b Hitachi 260-50, KBr method.

state polymerization as shown in Table III.

These differences in the cis-content in polymers obtained in the solution polymerization and in the solid state polymerization may depend on the polymerization mechanism, since a high stability of the intermediate radical in the solid state possibly induces the cistrans isomerization of the carbon-carbon double bond as below or a relative arrangement and the mobility of reacting molecules in the monomer crystals may affect the opening mode of the acetylenic triple bond.

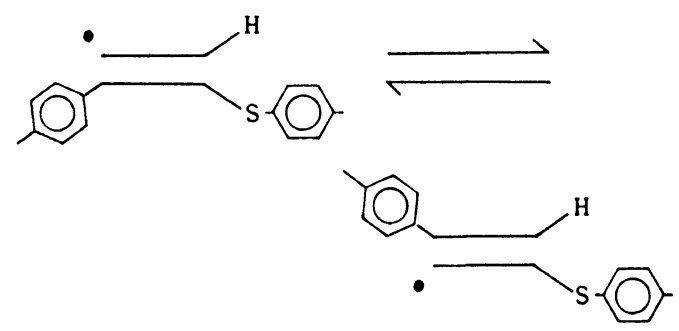

A configurational change by the cis-trans isomerization of the vinylene group of polymers may also occur during solid state polymerization. In fact, when the No. 2 sample in Table II (cis-content $99 \%$ ) is irradiated with the UV light from the high pressure mercury lamp for $5 \mathrm{hr}$ at $60^{\circ} \mathrm{C}$, the cis-content in polymers decreases about $20 \%$. The cis-content of the polymer obtained in the solid state polymerization decreased also from $82 \%$ of $\mathrm{cis}$ to $71 \%$ under thermal treatment at $95^{\circ} \mathrm{C}$ for $1 \mathrm{hr}$ under nitrogen atmosphere. However, the microstructures of polymers hardly changed at $70^{\circ} \mathrm{C}$. That is, the cis-trans isomerization of a polymer is induced by the photo-irradiation 
or by thermal treatment above $95^{\circ} \mathrm{C}$. Consequently, the effect of isomerization on the cis-content in the resultant polymer is not so important within a short polymerization time. The crystallinity of polymers obtained in the solid state polymerization also slightly decreases with increasing polymerization temperature. That is, the decrease of the ciscontent in polymers seems to induce decrease of crystallinity of polymers by destruction of the layer structures of polymers. This will be discussed later.

\section{REFERENCES}

1. E. P. Kohler and H. Potter, J. Am. Chem. Soc., 57, 1316 (1935).

2. J. March, "Advanced Organic Chemistry," Wiley and Sons, New York, N. Y., 1985, p 678.

3. J. R. Majer, J. Morton, and J. C. Robb, J. Chem.
Soc., B, 301 (1969).

4. F. W. Harris and M. W. Beltz, Am. Chem. Soc., Polym. Prepr., 27, 114 (1986).

5. E. Kobayashi, T. Ohashi, and J. Furukawa, Makromol. Chem., 187, 2525 (1986).

6. E. Kobayashi, T. Ohashi, and J. Furukawa, Polym. Prepr., Jpn., 33, 2507 (1984); ibid., 34, 731 (1985); J. Polym. Sci., Polym. Chem. Ed., 25, 2077 (1987).

7. E. Kobayashi, T. Ohashi, and J. Furukawa, Polym. Prep., Jpn., 35, 2654 (1986); to be published in $J$. Polym. Sci.

8. E. Kobayashi, T. Ohashi, and J. Furukawa, to be published in J. Polym. Sci.

9. E. Kobayashi, Y. Terada, T. Ohashi, and J. Furukawa, Polym. Prep., Jpn., 34, 2045 (1985); to be published in Polym. J.

10. A. A. Oswald, K. Griesbaum, B. H. Hudson, and J. M. Bregman, J. Am. Chem. Soc., 86, 2877 (1964).

11. L. J. Bellamy, "The Infrared Spectra of Complex Molecules," 2nd Ed., Wiley and Sons, New York, N. Y., 1985, (a) p 45 and (b) p 35.

12. Liu Yu-Cheng and Wang Sue-Kwung, Acta Chim. Sinica, 27, 113 (1961). 